\title{
Mild Chronic Hypoxia-Induced HIF-2a Interacts with c-MYC Through Competition with HIF-1a in Hepatocellular Carcinoma Proliferation
}

$\mathrm{Han} \mathrm{Mu}$

Tianjin Tumor Hospital

Ge Yu

Tianjin Tumor Hospital

Huikai Li

Tianjin Tumor Hospital

Mengmeng Wang

Ludwig-Maximilians-Universitat Munchen

Yunlong Cui

Tianjin Tumor Hospital

Ti Zhang

Tianjin Tumor Hospital

Tianqiang Song

Tianjin Tumor Hospital

Changfu Liu ( $\square$ doctorliuchangfu@163.com )

\section{Research}

Keywords: mild chronic hypoxia, HIF-1a, HIF-2a, c-MYC, Apitolisib, hepatocellular carcinoma

Posted Date: June 23rd, 2020

DOI: https://doi.org/10.21203/rs.3.rs-37458/v1

License: (c) (i) This work is licensed under a Creative Commons Attribution 4.0 International License.

Read Full License 


\section{Abstract}

Background: Hepatocellular carcinoma (HCC) has emerged as a major cause of cancer deaths globally, in which hypoxia and activated hypoxia-inducible factors (HIFs) play an important role. The sibling rivalry between HIF-1 $a$ and HIF-2a in hypoxic tumor growth and progression is still debated, including in HCC. This may be associated with the regulation of unique target genes, like c-MYC and mTOR.

Methods: In the current study, twenty-six corresponding tumor- and non-tumor tissues, taken from patients with HCC, who underwent liver resection, were analyzed. In vitro, co-immunoprecipitation (Co-IP), Western blot, MTT assay, colony formation assay and Annexin V-FITC/PI staining apoptosis Assay were used to elucidate the relationship between HIF-1 $a$ and HIF-2 $a$ in hypoxic HCC cell proliferation and involved mechanism.

Results: HIF-2a, but not HIF-1a, has a positive correlation with the expression of c-MYC in tumor tissues. In vitro, rapid HCC cell proliferation and increased interaction of HIF-2a/c-MYC were observed in mild chronic hypoxia. It was confirmed in situ proximity ligation assay and co-immunoprecipitation assay that although mild hypoxia up-regulated all HIF-1a, HIF-2a, and c-MYC, mTORC2-regulated HIF-2a competed with HIF-1 a to bind c-MYC. HIF-2a knockdown, but not HIF-1a knockdown, decreased the expression of downstream c-MYC and mTORC1, suppressed hypoxic cell proliferation, and induced more cell apoptosis. Moreover, the inhibition of upstream protein PI3K by inhibitor Apitolisib counteracted this mechanism of adaptation to mild hypoxia hereby inducing cancer cells to apoptosis in HCC.

Conclusions: In summary, this study highlights the role of HIF-2a but not HIF-1a in activating and binding c-MYC in HCC cell proliferation during mild chronic hypoxia response. PI3K/mTORC2/ HIF-2a/c-MYC axis plays a key role in this process. PI3K inhibitor Apitolisib is suggested as a potential treatment option for HCC, especially for rapidly growing HCC in mild chronic hypoxia.

\section{Introduction}

Hepatocellular carcinoma (HCC) has emerged as a major cause of cancer deaths globally and numbers are increasing $(1,2)$. Although anti-HCC treatments developed quickly in recent years, HCC behaves highly refractory to most anti-cancer therapies(3). Five-year survival of HCC patients remains dismal(4). To understand the mechanism of tumorigenesis and tumor resistance may provide a new therapeutic approach in HCC.

Recent studies indicated that rapid growth of tumors companied with intense metabolic activity, faulty vascularization, multiple nodules, and necrosis consumed a substantial amount of oxygen and therefore often caused a hypoxic microenvironment in $\operatorname{HCC}(5,6)$. Hypoxia, triggering a lot of molecular and cellular responses, is an important influencing factor for tumor aggressiveness and therapeutic response (7). In addition to transcatheter arterial (chemo) embolization (TAE/TACE), other anti-tumor treatments, including Sorafenib, were confirmed to increase Hypoxia in HCC, which is involved in tumor resistance and progression $(8,9)$. 
The major molecular mechanism elicits by hypoxia is through the stabilization of hypoxia-inducible factors (HIFs)(10). HIFs are heterodimeric complexes comprising a HIF-a subunit regulated through oxygen-dependent proteasomal degradation and a HIF- $\beta$ subunit constitutively expressed(10). Among them, the function and activity of HIF-a subunits -HIF- $1 a$, HIF- $2 a$, and HIF- $1 \beta$ are relatively well-studied. The overexpression of HIF-1a or HIF-2a has been detected in HCC patients and is closely associated with poor clinical outcome (6). HIF-1 a and HIF-2a share high sequence homology, but they regulate downstream genes independently and have different regulations in response to hypoxia in tumors(11-13). The two HIFa isoforms even appear to oppose each other on tumor cell proliferation(14). The sibling rivalry in hypoxic tumor growth and progression is mediated in part through the regulation of unique target genes, as well as interactions with important cellular pathways, including c-MYC and MTOR (15, 16).

C-MYC, an important role in cellular growth, differentiation, apoptosis, and metabolism, is indicated as an integral part of the HIF-a mediated hypoxic response $(15,17)$. Classic, HIF-1a regulates cell cycle and DNA repair genes through inhibiting of c-MYC activities; HIF-2a, in contrast, promotes cell proliferation by enhancing c-MYC activities(16). However, recent studies demonstrated that HIF-1a can cooperate with cMYC to induce the expression of specific target genes, including those encoding the glycolytic enzyme hexokinase 2 (HK2), pyruvate dehydrogenase kinase 1 (PDK1), and vascular endothelial growth factor $A$ (VEGFA) $(18,19)$. Moreover, c-MYC induces the expression of HIF-1a Posttranscriptionally in solid tumors, further proving that Hif-1a is downstream of c-MYC(19-21). Although HIF-1a is ubiquitously expressed, HIF-2a limited to endothelium, kidney, heart, lungs, small intestine, and liver $(22,23)$. Therefore, the relationship of HIF-1/2a with c-MYC in HCC is not yet clear.

This oppose effect between HIF-1 $a$ and HIF-2 $a$ is also shown in regulating the mechanistic target of rapamycin (mTOR) pathway, which plays a central role in physiology, metabolism, the aging process, and common diseases $(24,25)$. The mTOR kinase forms a complex with the cofactors and depending on whether it binds Raptor or Rictor, it forms mTORC1 or mTORC2, respectively (25). HIF-1a translation can be driven by growth factor-activated PI3K and mTOR1 $(26,27)$. Overexpressed HIF-1a may, in turn, have a negative feedback on mTORC1 activity. However, HIF-2a, being regulated by PI3K/mTORC2 but not $\mathrm{PI3K} / \mathrm{mTORC1}$, was confirmed to stimulate the expression of mTORC1 under hypoxic situation $(12,28$, 29). Additionally, it has been indicated the indispensable effect of either mTORC1 or mTORC2 on c-MYC activity $(30,31)$. An analysis of the mechanism that HIF-1a and HIF-2 $a$ antagonize one another to balance c-MYC in HCC responding to hypoxia may, therefore, provide insight into its rapid growth in hypoxic microenvironment; those insights could then lead to a new therapeutic approach for anti-tumor treatment of HCC.

\section{Materials And Methods}

\section{Human tissue}


Twenty-six corresponding tumor- and non-tumor tissues from patients with HCC who underwent liver resection were analyzed in the current study. This study was carried out with the patients' informed consent and approval from the local ethics committee. This approval is followed the guidelines stated in the Declaration of Helsinki. The clinical characteristics for all patients are provided in Table 1.

\begin{tabular}{|c|c|c|}
\hline Characteristic & Group & $N=26$ \\
\hline \multirow[t]{2}{*}{ Gender } & Male & 18 \\
\hline & Female & 8 \\
\hline Age (mean \pm SD) & $61.1 \pm 10.1$ & \\
\hline \multirow[t]{2}{*}{$\operatorname{AFP}(\mathrm{ng} / \mathrm{ml})$} & $\leq 400$ & 10 \\
\hline & $>400$ & 16 \\
\hline \multirow[t]{2}{*}{ Hepatitis (B/C) } & yes & 20 \\
\hline & no & 6 \\
\hline \multirow[t]{2}{*}{ Cirrhosis } & yes & 19 \\
\hline & no & 7 \\
\hline \multirow[t]{2}{*}{ Tumor size(cm) } & $\leq 5$ & 19 \\
\hline & $>5$ & 7 \\
\hline \multirow{2}{*}{ Tumor number } & Single & 13 \\
\hline & Multiple & 13 \\
\hline \multirow{2}{*}{ Child-Pugh class } & A & 23 \\
\hline & B & 3 \\
\hline \multirow[t]{2}{*}{ BCLC stage } & $0+A$ & 15 \\
\hline & B & 11 \\
\hline \multirow[t]{3}{*}{ TNM stage } & I & 10 \\
\hline & II & 9 \\
\hline & III & 7 \\
\hline
\end{tabular}


The slides were incubated overnight at $4{ }^{\circ} \mathrm{C}$ with the primary antibody at a concentration of $1 \mu \mathrm{g} / \mathrm{mL}$. After three washes, the tissue sections were incubated with $100 \mu \mathrm{L}$ of secondary antibody in a dark, humid chamber at room temperature for $1 \mathrm{~h}$. Finally, $100 \mu$ Lof4',6-diamidino-2-phenylindole (DAPI) solution (Sigma-Aldrich, St. Louis, MO, USA) was introduced into each tissue area for 10 min before being dehydrated and mounted. Immunofluorescence was examined using a Zeiss Axiovert $40 \mathrm{CFI}$ microscope and analyzed using the free ImageJ software (http://imagej.nih.gov/ij/).

\section{Cell culture and reagent}

The human HCC cell line HepG2 and Huh7 (ATCC, Manassas, Virginia, USA) were incubated in DMEM medium (Sigma-Aldrich, St. Louis, MO, USA) supplemented with $10 \%(\mathrm{v} / \mathrm{v})$ fetal bovine serum (Biochrom $\mathrm{GmbH}$, Darmstadt, Germany), $100 \mathrm{U} / \mathrm{ml}$ penicillin and $0.1 \mathrm{mg} / \mathrm{ml}$ streptomycin. The cells were cultured in

a $37^{\circ} \mathrm{C}$ humidified incubator with a $5 \% \mathrm{CO}^{2}$ atmosphere. The stock solution of Cobalt chloride $\left(\mathrm{CoCl}_{2}\right)$ (Sigma-Aldrich, St. Louis, MO, USA) with a concentration of $10 \mathrm{mM}$ was prepared using phosphatebuffered saline. Apitolisib (GDC-0980, RG7422, Selleck Chemicals, USA) were dissolved in $100 \%$ dimethyl sulfoxide and stored at $-20^{\circ} \mathrm{C}$.

\section{Cell viability assay}

$5 \times 10^{3}$ cells/well were seeded in a 96-well plate and treated. Cell viability was detected to calculate the $50 \%$ cell growth inhibitory concentrations (IC50) value after treatments for 24,48 and 72 hours. For analysis of cell proliferation after 6 days, HCC cells were seeded in 96 -well plates with $1 \times 10^{3}$ cells/well and treated. At the time points, $20 \mu \mathrm{L}$ of MTT (3-(4,5-dimethylthiazol-2-yl)-2,5-diphenyltetrazolium bromide, Sigma-Aldrich, St. Louis, MO, USA) solution was added to each well and incubated for $4 \mathrm{~h}$ before the MTT metabolic product was resuspended in $200 \mu \mathrm{L}$ of 2-propanol (Sigma-Aldrich, St. Louis, MO, USA). Then, the optical density was read at $570 \mathrm{~nm}$.

\section{Colony-formation assay}

Cells (400 cells/well) were plated in 6-well plates. After treatment conditions for 14 days, cells were fixed and stained using crystal violet ( $20 \%$ ethanol and $0.5 \%$ crystal violet in water). The number of colonies, defined as $>50$ cells/colony, were counted.

\section{In situ Proximity Ligation Assay (PLA assay)}

All cells were pipetted into 8-well culture slides. After treatments, cells were fixed, permeabilized, and blocked. Primary antibodies were incubated with the cells overnight at $4^{\circ} \mathrm{C}$. Afterward, PLA MINUS and PLA PLUS probes were added. The ligation solvent and ligase were mixed and then incubated before the final amplification solution was added into cells. Samples were detected using a fluorescence microscope and counted with BolbFinder Software (http://www.cb.uu.se/ amin/BlobFinder/).

\section{Co-Immunoprecipitation (Co-IP)}


Cells were transfected with the plasmid of Flag-HIF-1 $a$ and Flag-HIF-2a (Sino Biological, Wayne, PA, USA). After 48 hours of transfection, stably transfected cells were selected and treated. Afterward, the following steps were carried out by the manufacturer's protocol of the Pierce ${ }^{\mathrm{TM}}$ Co-Immunoprecipitation-Kit (Thermo Scientific, Waltham, MA, USA). Cell lysates were immunoprecipitated with Flag or c-MYC antibody and the expression of Flag and c-MYC in the eluate were detected by western blot analysis.

\section{Western blotting}

Cells were lysed using RIPA buffer (Sigma-Aldrich, St. Louis, MO, USA) for 10 min on ice, followed by centrifugation. The supernatant was collected, and the protein concentration was determined using a BCA $^{\text {TM }}$ Protein Assay Kit (Thermo Scientific, Rockford, IL, USA). Whole-cell extracts $(20 \mu \mathrm{g})$ were heated with LDS sample buffer (Invitrogen, Carlsbad, CA, USA) at $70^{\circ} \mathrm{C}$ for $10 \mathrm{~min}$, separated using SDS polyacrylamide gel electrophoresis in 4-12\% Bis-Tris gel (Invitrogen, Carlsbad, CA, USA), and transferred to the nitrocellulose membrane (Bio-Rad, Hercules, CA, USA). After blocking for $1 \mathrm{~h}$, the membrane was incubated overnight with primary antibodies at $4{ }^{\circ} \mathrm{C}$. Subsequently, the membrane was probed using IRDye ${ }^{\circledR}$ 680RD Goat anti-Mouse/Rabbit IgG secondary antibody (LI-COR Biosciences, Lincoln, Nebraska, USA) for $1 \mathrm{~h}$ at room temperature. The membranes were visualized using an Odyssey CLx scanner (LICOR Bioscience, Lincoln, Nebraska, USA) and the results were obtained using Image Studio software (LICOR Bioscience, Lincoln, Nebraska, USA).

\section{Short hairpin RNA (shRNA) Transfection}

Cells were seeded at a density of $1.5 \times 10^{5}-2.5 \times 10^{5}$ in 6-well plates and incubated overnight with normal growth medium without antibiotics. Subsequent detailed steps were operated by the protocol from Santa Cruz Biotechnology (Santa Cruz, CA, USA). 48 hours after transfection, the medium was aspirated and replaced with fresh medium containing $1 \mu \mathrm{g} / \mathrm{ml}$ puroMYCin every 3 days to select stably transfected cells.

\section{Apoptosis}

Cells $\left(1 \times 10^{6}\right.$ cells/well $)$ were seeded in six-well plates and treated. The treated cells were harvested onto ice and fixed. Then the cells were incubated with PI stock solution in the dark for 30 min at room temperature. the sub-G1 cell fraction of activated cells was detected by FACS Calibur (BD Biosciences, San Jose, CA, USA) and the data was analyzed with Flowjo Software (www.flowjo.com).

\section{Scratch Wound Assay}

During cells were treated, the time-lapse images for each position in the wells were analyzed and the wound areas were measured to determine the percentage of wound closure at several time points throughout the course of the assay. To ensure that the similar wound areas were compared, the produced wound area was traced and measured by using ImageJ software(http://imagej.nih.gov/ij/).

\section{Antibodies}


The following antibodies were used: Actin (3700S), HIF-1a (36169S), c-MYC (5605S), Phospho-mTOR (5536S), Cleaved Caspase 8 (9748S), Cleaved Caspase 3 (9664S), and Cleaved Caspase 9 (20750S), PI3K (4249S), Akt (4691S), Phospho-AKT (9271S) and FADD (2782S) from Cell Signaling Technology, Danvers, Massachusetts, USA; HIF-2a/ EPAS-1 (sc-13596), Raptor (sc-81537), and Rictor (sc-271081) from Santa Cruz Biotechnology, Dallas, Texas, USA; the secondary antibodies for goat anti-rabbit and goat anti-mouse from LI-COR Biosciences GmbH, Bad Homburg, Germany.

\section{Statistical Analysis}

The IC50, t-test, and one-way analysis of variance were calculated, and the figures were plotted using GraphPad Prism 7.0. The values obtained are the mean ( \pm SEM) of three replicates. Statistical difference was considered significant when $p<0.05$.

\section{Results}

\section{HIF-2a, but not HIF-1a,has a positive correlation with the expression of c-MYC in HCC patients}

To evaluate the correlation between HIF-1/2a and c-MYC, the expression of HIF-1a, HIF-2a, c-MYC, Rictor and Raptor were detected in 26 patients diagnosed with HCC (Fig. 1A-B). The highly expressed targets above in tumor tissues compared to corresponding non-tumor tissues were confirmed to be associated with the degree of tumor stage (Fig. 1C). Especially, the average expression of c-MYC in tumor tissues was up-regulated at all UICC stages aberrantly. In correlation analysis, the positive relationships between HIF-2 $a$ and c-MYC, HIF-2 $a$ and Rictor, Rictor and c-MYC, HIF-1 $a$ and Raptor were confirmed (score $>0.5$, Fig. 1D). Moreover, the linear correlation between HIF-2 $a$ and c-MYC was double-check $(r=0.7772, P<$ 0.0001 , Fig. 1E). This suggests that HIF-2a, not HIF-1a, correlates its expression with c-MYC.

In the analysis of the expressions of targets at each UICC stage, unlike other proteins, the increasing number of patients with high expressed HIF-2a was tumor stage-dependent (Fig. 1F-G, s Fig. 1A-B). Kaplan-Meier survival analysis from HCC public gene database further showed that high HIF-2a, compared to other targets, is more closely related to a poor overall survival (Fig. $1 \mathrm{H})$. These data point to the important role of HIF-2a, but not HIF-1a, in tumorigenesis and correlations with c-MYC.

\section{Rapid cell proliferation and increased interaction of HIF-2a/c-MYC in HCC under mild and chronic hypoxia}

In vitro, $\mathrm{Cocl}_{2}$ was introduced into $\mathrm{HCC}$ cell lines Huh7 and HepG2 to create a hypoxic environment. The $\mathrm{IC}_{50}$ values of $\mathrm{Cocl}_{2}\left(\mathrm{Cocl}_{2}{ }^{\mathrm{IC} 50}\right)$ were identified by the cell viability assay (Fig. $\left.2 \mathrm{~A}\right)$. Interestingly, cellular proliferation under hypoxia with a low concentration of $50 \mu \mathrm{M}\left(\mathrm{Cocl}_{2}{ }^{\text {low }}\right)$ was observed and was further evaluated when the exposure time of cells to $\mathrm{Cocl}_{2}{ }^{\text {low }}$ prolonged to 6 Days. Cancer cells showed the rapid growth under low hypoxia condition, together with high expression of HIF-1a, HIF-2a, c-MYC, Rictor and Raptor (Fig. 2B-C). The ability of cellular proliferation in response to low hypoxia was also confirmed by clonogenicity assays showing a low hypoxia-induced increase in the number and size of colonies in Huh7 
and HepG2 cells upon incubation with $\mathrm{Cocl}_{2}{ }^{\text {low }}$. $\mathrm{Cocl}_{2}{ }^{\mathrm{IC} 50}$ inhibited the total clone formation rate remarkably (Fig. 2D).

To investigate the relationship between activated HIF-1/2a and highly expressed c-MYC, a Co-IP assay was applied and indicated that the HIF-2a/c-MYC interaction significantly increased under mild hypoxia compared to the HIF-1a/c-MYC interaction (Fig. 2E). Likewise, active interaction of HIF-2a/c-MYC and noninteraction of HIF-1a/c-MYC was confirmed in PLA assay analysis (Fig. 2F). These results indicate that although hypoxia condition up-regulates all HIF-1a, HIF-2a, and c-MYC, HIF-2a seems to compete with HIF-1 a to interact with c-MYC.

\section{HIF-2a enhances c-MYC and mTORC1 activities and its key role in hypoxic cell proliferation}

To study further this "competition" between HIF-1a and HIF-2a, shRNA transfection targeting HIF-1a and HIF-2a (Gene: EPAS1) was conducted in Huh7 and HepG2 cell lines (s Fig. 2A). Unlike that HIF-1a silencing did not affect the protein levels of HIF-2a, c-MYC, Rictor, Raptor and phosphorylation of mTOR, HIF-2a knockdown significantly decreased the expression of c-MYC, Raptor, and phosphorylation of mTOR, but not Rictor and HIF-1a (Fig. 3A-B). Two non-redundant complexes of mTOR have been described: mTORC1 containing Raptor and mTORC2 containing Rictor (Fig. 3C)(25). These results above explained that up-regulated expressions of c-MYC and Raptor by hypoxia can be inhibited when HIF-2a was knockdown, suggesting that c-MYC and mTORC1 are the downstream of HIF-2a. Furthermore, more interaction of HIF-1 a/c-MYC was observed in shHIF-2a transfected cells under hypoxia condition (Fig. 3DE). On the contrary, HIF-1a knockdown promoted the protein binding between HIF-2a and c-MYC. This demonstrated that highly expressed HIF-2a counteracts HIF-1a to interact with c-MYC in hypoxia.

To confirm that HIF-2a is a key in hypoxic cell proliferation, the cell viability, migration, and apoptosis of shHIF-1/2a transfected cells under low hypoxia conditions were evaluated. Compared to HIF-1a knockdown, HIF-2a knockdown inhibited hypoxic cell growth more significantly (Fig. 4A). Also, shHIF-2a cancer cells had low cellular migration and more apoptosis (Fig. 4B-E). The induced apoptosis in hypoxic cells through silencing HIF-2a was also confirmed by up-regulated protein levels of apoptotic proteins: FADD, cleaved caspase 3, cleaved caspase 8, and cleaved caspase 9 (Fig. 4F). Therefore, HIF-2a knockdown may reverse and sensitize cancer cells to hypoxia-induced apoptosis.

\section{HIF-2 $a$ is regulated by $\mathrm{PI} 3 \mathrm{~K} / \mathrm{mTORC2}$ in response to hypoxia}

Since that HIF-2a knockdown does not affect the expression of Rictor, and recent studies indicated that $\mathrm{PI3K} / \mathrm{mTORC} 2$ regulates transcription of HIF-2a/EPAS1 in neuroblastoma(32). Here, we hypothesized that mTORC2, as an upstream protein, regulates the expression of HIF-2a in HCC responding to hypoxia. As shown in results, the pathway of PI3K/AKT/mTOR was activated in cell lines Huh7 and HepG2 after exposure to $\mathrm{Cocl}_{2}{ }^{\text {low }}$ treatment (Fig. 5A). shRNA targeting Rictor was applied to decrease the formation of mTOR complexes-mTORC2 (s Fig. 3A). Rictor knockdown inhibited the phosphorylation of mTOR and Akt, followed by down-regulated expression of Rictor, HIF-2a, and c-MYC in $\mathrm{Cocl}_{2}{ }^{\text {low }}$ treated cells (Fig. 5B). 
Furthermore, the interaction of both HIF-1a/c-MYC and HIF-2a/c-MYC was suppressed in shRictor transfected cells (Fig. 5C-D). Compared with untreated cells and hypoxic cells, cell proliferation was reduced after knockdown of Rictor (Fig. 5E). Additionally, shRictor transfected cells was shown to have a lower cell viability than shHIF-2a transfected cells in response to hypoxia. Altogether, these data support the hypothesis that mTORC2 plays a key role in promoting hypoxic cell proliferation by up-regulating the expressions and interaction of downstream HIF-2a and c-MYC in HCC.

\section{The PI3K inhibitor Apitolisib induce hypoxic cell death in HCC}

The involvement of the PI3K/mTORC2 pathway in response to hypoxia suggests that blockade of this pathway may be a promising approach for the treatment of HCC. Here, Apitolisib (GDC-0980), a recently developed PI3K inhibitor for the treatment of solid tumors, was introduced and assessed its antineoplastic effect on HCC under hypoxia(33-35). Apitolisib treatment was shown to cause a dosedependent loss in cell viability in Huh7 and HepG2 (Fig. 6A). Under hypoxia condition, Apitolisib at IC50 value concentration (Apitolisib ${ }^{\text {IC50}}$ ) blocked the activities of PI3K, Raptor, Rictor, HIF-1/2a, and c-MYC; and then inhibited cell growth (Fig. 6B-C). In FACS analysis, sub-G1 cell fraction detection was increased in Apitolisib treated hypoxic cells (Fig. 6D-E). This induction of apoptosis was also observable in DAPI stained cells, which showed apoptotic features, such as DNA fragments (Fig. 6F). These results were clearly confirmed by highly expressed apoptotic proteins: FADD, cleaved caspase 3 , cleaved caspase 8 , and cleaved caspase 9 in cells upon incubation with $\mathrm{Coc} 2^{\mathrm{low}}$ and Apitolisib ${ }^{\mathrm{IC50}}$ (Fig. 6G). Taken together, these data above indicate that PI3k inhibition by Apitolisib counteracts the mechanism of adaptation to hypoxia hereby inducing cancer cells to apoptosis in HCC.

\section{Discussion}

HIFs are broadly expressed and associated with poor prognosis in human cancers(10). There is now mounting evidence that its subunits HIF- $1 a$ and HIF-2a can promote highly opposing outcomes $(15,36)$. Specifically, the effect of HIF-2a on c-MYC is of interest, as it directly opposes that of HIF-1a, allowing differential control of tumorigenesis and tumor development based on the HIF-a subunit expression(37). However, a more complex question emerged as both HIF-1a and HIF-2a protein expression are coexpressed in multiple tumor types including $\mathrm{HCC}$, suggesting that understanding their relationship and the mechanism of regulating c-MYC need to be further studied $(6,23)$.

In the current study, the correlation of HIF-2a, but not HIF-1a, with c-MYC was confirmed in tumor tissues from 25 patients with HCC. The expression of HIF-2 $a$ increased UICC stage-dependently, which suggests the role of HIF-2 $a$ in tumor development. In a previous study, high expressed HIF-2a was detected in HCC and adjacent noncancerous tissues, but not in normal liver tissues, which is positively associated with shorter overall survival(38). This is similar to our Kaplan-Meier survival analysis of the HCC gene dataset from TCGA. Moreover, increasing evidences speculate a positive regulatory role for HIF-2a in fibrosis, pathogenesis, metastasis, and resistance to anti-tumor treatments in $\mathrm{HCC}(22,39-44)$. Taken together, HIF2a may be a potential target for the treatment of HCC. 
The role of HIF-2a in HCC was also investigated both in vitro and in vivo that siRNA-mediated knockdown of HIF-2a in HepG2 cells impaired cell cycle progression in the presence of $\mathrm{CoCl}_{2}$ and reduced cell proliferation (45). HCC mice lacking HIF2 $a$ in myeloid cells showed decreased infiltration of tumorassociated macrophages and delayed tumor progression(46). Here, HCC cells were shown as rapid growth in response to mild and long hypoxia, and highly expressed all HIF-1a, HIF-2a, and c-MYC. It was reported before that knockdown of HIF-1 $a$ increased HIF-2 $a$ and that knockdown of HIF-2a increased HIF$1 a$ in HCC cells, suggesting a balance between HIF-1a and HIF-2a in HCC cells(47). In this study, HIF-2a was further confirmed to have a competed ability with HIF-1a to interact with c-MYC. More interaction of HIF-2a with c-MYC and non-interaction of HIF-1a with c-MYC was observed in hypoxic cells. This suggests that the balance between HIF-1a and HIF-2a seems to be based on interacting with c-MYC rather than simply regulating the expression of HIF-1a or HIF-2a.

In addition, it's HIF-2a knockdown that inhibited HCC cell proliferation and the expression of c-MYC under mild hypoxia remarkably, rather than HIF-1a knockdown. Similar results were to be found in renal tumor that HIF-2 $a$ actually increases c-MYC transcriptional activity to promote cell growth, HIF-1a does not (37, $48,49)$. This may due to that HIF-2a levels may increase over time in hypoxia and play a role during mild, chronic hypoxia $(50,51)$. Oxygenation in solid tumors varies from physiologic levels of approximately $5 \%$ to $8 \% \mathrm{O}_{2}$ to near anoxia(52). Tumor hypoxia therefore is also highly heterogeneous with both chronic and acute hypoxia(53). It was demonstrated that HIF-1 a seems to have the dominant role in controlling responses to acute hypoxia, whereas HIF-2a is responsible for low or chronic hypoxia(51). The low and prolonged hypoxia increased transcription of HIF-2a consistently, whereas suppressed transcription of HIF-1a(54). Mechanistically, this may due to HIF-1a feedback regulation by prolyl-4-hydroxylase (PHD) under chronic hypoxia at $1 \% \mathrm{O}_{2}$; increased acetylation of the core histones $\mathrm{H} 3$ and $\mathrm{H} 4$ within proximal promoter region HIF-2a; and switch from HIF-1 $a$ to HIF-2a by hypoxia-associated factor (54-56). Increased HIF2 $a$ forms a complex with MAX, causing a dose-dependent stabilization of MYC-MAX and MYC-MAXSP1 complexes, resulting in promoting c-MYC expression and its binding with MAX. These effects occur rapidly and can be detected after only $1-2$ hours at $0.5 \% \mathrm{O}_{2}(15)$.

mTORC2, activated by upstream PI3K, regulates the expression of HIF-2a in neuroblastoma $(25,32)$. VHLdeficient RCC cells that constitutively express HIF-2a have been also shown to have a separate dependency on mTORC1 and mTORC2 for HIF-1a and HIF-2a expression(57). Here, Rictor knockdown significantly inhibited the form of mTORC2, followed by decreasing the activities of HIF-2a and c-MYC. This shows that HIF-2a expression is regulated by hypoxia via the PI3K/ mTORC2 pathway in HCC cells. Because the PI3K pathway appears to be a major activator of HIF2 activity and PI3K/mTOR inhibitors are in clinical use and late clinical trials(58). A new PI3K inhibitor Apitolisib was applied in this study and has been shown to suppress the PI3K/mTORC2/ HIF-2a/c-MYC axis and strongly induce apoptosis in HCC cells under mild and long hypoxia. This suggests that Apitolisib is considered as a potential treatment option for HCC, especially for rapidly growing HCC in low and chronic hypoxia.

\section{Conclusions}


In summary, this study highlights the role of HIF-2a but not HIF-1a in activating and binding c-MYC in $\mathrm{HCC}$ cell proliferation during mild and chronic hypoxia response. PI3K/mTORC2/ HIF-2a/c-MYC axis plays a key role in this process (Figure 7). PI3K inhibitor Apitolisib is suggested as a potential treatment option for HCC, especially for rapidly growing HCC in mild and chronic hypoxia.

\section{Abbreviations}

Hepatocellular carcinoma: HCC; hypoxia-inducible factors: HIFs; arterial (chemo) embolization: TAE/TACE; hexokinase 2: HK2; pyruvate dehydrogenase kinase 1: PDK1; vascular endothelial growth factor A: VEGFA; 4',6diamidino-2-phenylindole: DAPI; Cobalt chloride: $\mathrm{CoCl} 2 ; 50 \%$ cell growth inhibitory concentrations: IC50; Short hairpin RNA: shRNA.

\section{Declarations}

\section{ACKNOWLEDGEMENTS}

We appreciated the technical support from Mr. Andreas Ziesch and Ms. Weiwei Ma.

\section{AUTHORS' CONTRIBUTIONS}

$\mathrm{HM}$ and $\mathrm{CFL}$ conceived the project. $\mathrm{HM}$ and $\mathrm{CFL}$ performed all experiments and constructed the manuscript. MMW and TZ support the experimental techniques. HKL, GY and YLC collected clinical sample and information. CFL and TQS supervised all studies. All authors participated in preparing the manuscript and approved the submitted and published version.

\section{FUNDING}

This work was supported by the funding form Tianjin Medical University Cancer Institute and Hospital, Tianjin, China (NO. TJ20170110).

\section{AVAILABILITY OF DATA AND MATERIALS}

The data used and analyzed during the current study are available from the corresponding author on reasonable request.

\section{ETHICS APPROVAL AND CONSENT TO PARTICIPATE}

All of our experiments involving human participants were approved by The Ethics Committee of Tianjin Medical University and performed in accordance with the Declaration of Helsinki. We obtained human $\mathrm{HCC}$ tissue and adjacent normal tissue from HCC patients at the Tianjin Medical University Cancer Institute and Hospital with all patient's informed consent. 
Not applicable.

\section{COMPETING INTERESTS}

The authors declare that they have no conflict of interest.

\section{References}

1. Forner A, Reig M, Bruix J. Hepatocellular carcinoma. Lancet. 2018;391(10127):1301-14.

2. Villanueva A. Hepatocellular Carcinoma. N Engl J Med. 2019;380(15):1450-62.

3. Llovet JM, Montal R, Sia D, Finn RS. Molecular therapies and precision medicine for hepatocellular carcinoma. Nat Rev Clin Oncol. 2018;15(10):599-616.

4. Siegel RL, Miller KD, Jemal A. Cancer statistics, 2020. CA Cancer J Clin. 2020;70(1):7-30.

5. McKeown SR. Defining normoxia, physoxia and hypoxia in tumours-implications for treatment response. Br J Radiol. 2014;87(1035):20130676.

6. Wilson GK, Tennant DA, McKeating JA. Hypoxia inducible factors in liver disease and hepatocellular carcinoma: current understanding and future directions. J Hepatol. 2014;61(6):1397-406.

7. Chen C, Lou T. Hypoxia inducible factors in hepatocellular carcinoma. Oncotarget. 2017;8(28):46691703.

8. Mendez-Blanco C, Fondevila F, Garcia-Palomo A, Gonzalez-Gallego J, Mauriz JL. Sorafenib resistance in hepatocarcinoma: role of hypoxia-inducible factors. Exp Mol Med. 2018;50(10):1-9.

9. Tang L, Zeng J, Geng P, Fang C, Wang Y, Sun M, et al. Global Metabolic Profiling Identifies a Pivotal Role of Proline and Hydroxyproline Metabolism in Supporting Hypoxic Response in Hepatocellular Carcinoma. Clin Cancer Res. 2018;24(2):474-85.

10. Semenza GL. Hypoxia-inducible factors in physiology and medicine. Cell. 2012;148(3):399-408.

11. Helczynska K, Larsson AM, Holmquist Mengelbier L, Bridges E, Fredlund E, Borgquist S, et al. Hypoxia-inducible factor-2alpha correlates to distant recurrence and poor outcome in invasive breast cancer. Cancer Res. 2008;68(22):9212-20.

12. Noguera R, Fredlund E, Piqueras M, Pietras A, Beckman S, Navarro S, et al. HIF-1alpha and HIF2alpha are differentially regulated in vivo in neuroblastoma: high HIF-1 alpha correlates negatively to advanced clinical stage and tumor vascularization. Clin Cancer Res. 2009;15(23):7130-6.

13. Kim WY, Perera S, Zhou B, Carretero J, Yeh JJ, Heathcote SA, et al. HIF2alpha cooperates with RAS to promote lung tumorigenesis in mice. J Clin Invest. 2009;119(8):2160-70.

14. Qin N, de Cubas AA, Garcia-Martin R, Richter S, Peitzsch M, Menschikowski M, et al. Opposing effects of HIF1alpha and HIF2alpha on chromaffin cell phenotypic features and tumor cell proliferation: Insights from MYC-associated factor X. Int J Cancer. 2014;135(9):2054-64.

15. Keith B, Johnson RS, Simon MC. HIF1alpha and HIF2alpha: sibling rivalry in hypoxic tumour growth and progression. Nat Rev Cancer. 2011;12(1):9-22. 
16. Huang LE. Carrot and stick: HIF-alpha engages c-Myc in hypoxic adaptation. Cell Death Differ. 2008;15(4):672-7.

17. Dang CV. c-Myc target genes involved in cell growth, apoptosis, and metabolism. Mol Cell Biol. 1999;19(1):1-11.

18. Kim JW, Gao P, Liu YC, Semenza GL, Dang CV. Hypoxia-inducible factor 1 and dysregulated c-Myc cooperatively induce vascular endothelial growth factor and metabolic switches hexokinase 2 and pyruvate dehydrogenase kinase 1. Mol Cell Biol. 2007;27(21):7381-93.

19. Zhang J, Sattler M, Tonon G, Grabher C, Lababidi S, Zimmerhackl A, et al. Targeting angiogenesis via a c-Myc/hypoxia-inducible factor-1 alpha-dependent pathway in multiple myeloma. Cancer Res. 2009;69(12):5082-90.

20. Doe MR, Ascano JM, Kaur M, Cole MD. Myc posttranscriptionally induces HIF1 protein and target gene expression in normal and cancer cells. Cancer Res. 2012;72(4):949-57.

21. Chen C, Cai S, Wang G, Cao X, Yang X, Luo X, et al. c-Myc enhances colon cancer cell-mediated angiogenesis through the regulation of HIF-1a. Biochemical and biophysical research communications. 2013;430(2):505-11.

22. Ma L, Li G, Zhu H, Dong X, Zhao D, Jiang X, et al. 2-Methoxyestradiol synergizes with sorafenib to suppress hepatocellular carcinoma by simultaneously dysregulating hypoxia-inducible factor- 1 and -2. Cancer Lett. 2014;355(1):96-105.

23. Wiesener MS, Jurgensen JS, Rosenberger C, Scholze CK, Horstrup JH, Warnecke C, et al. Widespread hypoxia-inducible expression of HIF-2alpha in distinct cell populations of different organs. FASEB J. 2003;17(2):271-3.

24. Sabatini DM. Twenty-five years of mTOR: Uncovering the link from nutrients to growth. Proc Natl Acad Sci U S A. 2017;114(45):11818-25.

25. Laplante M, Sabatini DM. mTOR signaling at a glance. J Cell Sci. 2009;122(Pt 20):3589-94.

26. Liu P, Cheng H, Roberts TM, Zhao JJ. Targeting the phosphoinositide 3-kinase pathway in cancer. Nat Rev Drug Discov. 2009;8(8):627-44.

27. Dodd KM, Yang J, Shen MH, Sampson JR, Tee AR. mTORC1 drives HIF-1 alpha and VEGF-A signalling via multiple mechanisms involving 4E-BP1, S6K1 and STAT3. Oncogene. 2015;34(17):2239-50.

28. Melendez-Rodriguez F, Roche 0 , Sanchez-Prieto R, Aragones J. Hypoxia-Inducible Factor 2-Dependent Pathways Driving Von Hippel-Lindau-Deficient Renal Cancer. Front Oncol. 2018;8:214.

29. Cam H, Easton JB, High A, Houghton PJ. mTORC1 signaling under hypoxic conditions is controlled by ATM-dependent phosphorylation of HIF-1alpha. Mol Cell. 2010;40(4):509-20.

30. Xu Z, Xu M, Liu P, Zhang S, Shang R, Qiao Y, et al. The mTORC2-Akt1 Cascade Is Crucial for c-Myc to Promote Hepatocarcinogenesis in Mice and Humans. Hepatology. 2019;70(5):1600-13.

31. Liu P, Ge M, Hu J, Li X, Che L, Sun K, et al. A functional mammalian target of rapamycin complex 1 signaling is indispensable for c-Myc-driven hepatocarcinogenesis. Hepatology. 2017;66(1):167-81. 
32. Mohlin S, Hamidian A, von Stedingk K, Bridges E, Wigerup C, Bexell D, et al. PI3K-mTORC2 but not PI3K-mTORC1 regulates transcription of HIF2A/EPAS1 and vascularization in neuroblastoma. Cancer Res. 2015;75(21):4617-28.

33. Powles T, Lackner MR, Oudard S, Escudier B, Ralph C, Brown JE, et al. Randomized Open-Label Phase II Trial of Apitolisib (GDC-0980), a Novel Inhibitor of the PI3K/Mammalian Target of Rapamycin Pathway, Versus Everolimus in Patients With Metastatic Renal Cell Carcinoma. J Clin Oncol. 2016;34(14):1660-8.

34. Dolly SO, Wagner AJ, Bendell JC, Kindler HL, Krug LM, Seiwert TY, et al. Phase I Study of Apitolisib (GDC-0980), Dual Phosphatidylinositol-3-Kinase and Mammalian Target of Rapamycin Kinase Inhibitor, in Patients with Advanced Solid Tumors. Clin Cancer Res. 2016;22(12):2874-84.

35. Makker V, Recio FO, Ma L, Matulonis UA, Lauchle JO, Parmar H, et al. A multicenter, single-arm, openlabel, phase 2 study of apitolisib (GDC-0980) for the treatment of recurrent or persistent endometrial carcinoma (MAGGIE study). Cancer. 2016;122(22):3519-28.

36. Morris MR, Hughes DJ, Tian YM, Ricketts CJ, Lau KW, Gentle D, et al. Mutation analysis of hypoxiainducible factors HIF1A and HIF2A in renal cell carcinoma. Anticancer Res. 2009;29(11):4337-43.

37. Gordan JD, Bertout JA, Hu CJ, DiehI JA, Simon MC. HIF-2alpha promotes hypoxic cell proliferation by enhancing c-myc transcriptional activity. Cancer Cell. 2007;11(4):335-47.

38. Bangoura G, Liu ZS, Qian Q, Jiang CQ, Yang GF, Jing S. Prognostic significance of HIF-2alpha/EPAS1 expression in hepatocellular carcinoma. World J Gastroenterol. 2007;13(23):3176-82.

39. Wei K, Piecewicz SM, McGinnis LM, Taniguchi CM, Wiegand SJ, Anderson K, et al. A liver Hif-2alphaIrs2 pathway sensitizes hepatic insulin signaling and is modulated by Vegf inhibition. Nat Med. 2013;19(10):1331-7.

40. Anavi S, Hahn-Obercyger M, Madar Z, Tirosh O. Mechanism for HIF-1 activation by cholesterol under normoxia: a redox signaling pathway for liver damage. Free Radic Biol Med. 2014;71:61-9.

41. Asai Y, Yamada T, Tsukita S, Takahashi K, Maekawa M, Honma M, et al. Activation of the Hypoxia Inducible Factor 1alpha Subunit Pathway in Steatotic Liver Contributes to Formation of Cholesterol Gallstones. Gastroenterology. 2017;152(6):1521-35 e8.

42. Hu W, Zheng S, Guo H, Dai B, Ni J, Shi Y, et al. PLAGL2-EGFR-HIF-1/2alpha signaling loop promotes HCC progression and Erlotinib insensitivity. Hepatology. 2020.

43. Qu A, Taylor M, Xue X, Matsubara T, Metzger D, Chambon P, et al. Hypoxia-inducible transcription factor 2alpha promotes steatohepatitis through augmenting lipid accumulation, inflammation, and fibrosis. Hepatology. 2011;54(2):472-83.

44. Wang X, Dong J, Jia L, Zhao T, Lang M, Li Z, et al. HIF-2-dependent expression of stem cell factor promotes metastasis in hepatocellular carcinoma. Cancer Lett. 2017;393:113-24.

45. He C, Sun XP, Qiao H, Jiang X, Wang D, Jin X, et al. Downregulating hypoxia-inducible factor-2alpha improves the efficacy of doxorubicin in the treatment of hepatocellular carcinoma. Cancer Sci. 2012;103(3):528-34. 
46. Imtiyaz HZ, Williams EP, Hickey MM, Patel SA, Durham AC, Yuan LJ, et al. Hypoxia-inducible factor 2alpha regulates macrophage function in mouse models of acute and tumor inflammation. $\mathrm{J}$ Clin Invest. 2010;120(8):2699-714.

47. Menrad H, Werno C, Schmid T, Copanaki E, Deller T, Dehne N, et al. Roles of hypoxia-inducible factor1 alpha (HIF-1alpha) versus HIF-2alpha in the survival of hepatocellular tumor spheroids. Hepatology. 2010;51(6):2183-92.

48. Koshiji M, To KK, Hammer S, Kumamoto K, Harris AL, Modrich P, et al. HIF-1 alpha induces genetic instability by transcriptionally downregulating MutSalpha expression. Mol Cell. 2005;17(6):793-803.

49. Koshiji M, Kageyama Y, Pete EA, Horikawa I, Barrett JC, Huang LE. HIF-1alpha induces cell cycle arrest by functionally counteracting Myc. EMBO J. 2004;23(9):1949-56.

50. Lofstedt T, Fredlund E, Holmquist-Mengelbier L, Pietras A, Ovenberger M, Poellinger L, et al. Hypoxia inducible factor-2alpha in cancer. Cell Cycle. 2007;6(8):919-26.

51. Holmquist-Mengelbier L, Fredlund E, Lofstedt T, Noguera R, Navarro S, Nilsson H, et al. Recruitment of HIF-1 alpha and HIF-2alpha to common target genes is differentially regulated in neuroblastoma: HIF2alpha promotes an aggressive phenotype. Cancer Cell. 2006;10(5):413-23.

52. Vaupel $\mathrm{P}$, Hockel M, Mayer A. Detection and characterization of tumor hypoxia using $\mathrm{pO} 2$ histography. Antioxid Redox Signal. 2007;9(8):1221-35.

53. Dewhirst MW, Cao Y, Moeller B. Cycling hypoxia and free radicals regulate angiogenesis and radiotherapy response. Nat Rev Cancer. 2008;8(6):425-37.

54. Lin Q, Cong X, Yun Z. Differential hypoxic regulation of hypoxia-inducible factors 1alpha and 2alpha. Mol Cancer Res. 2011;9(6):757-65.

55. Henze AT, Riedel J, Diem T, Wenner J, Flamme I, Pouyseggur J, et al. Prolyl hydroxylases 2 and 3 act in gliomas as protective negative feedback regulators of hypoxia-inducible factors. Cancer Res. 2010;70(1):357-66.

56. Koh MY, Lemos R, Jr., Liu X, Powis G. The hypoxia-associated factor switches cells from HIF-1alphato HIF-2alpha-dependent signaling promoting stem cell characteristics, aggressive tumor growth and invasion. Cancer Res. 2011;71(11):4015-27.

57. Toschi A, Lee E, Gadir N, Ohh M, Foster DA. Differential dependence of hypoxia-inducible factors 1 alpha and 2 alpha on mTORC1 and mTORC2. J Biol Chem. 2008;283(50):34495-9.

58. LoRusso PM. Inhibition of the PI3K/AKT/mTOR Pathway in Solid Tumors. J Clin Oncol. 2016;34(31):3803-15.

\section{Figures}


A

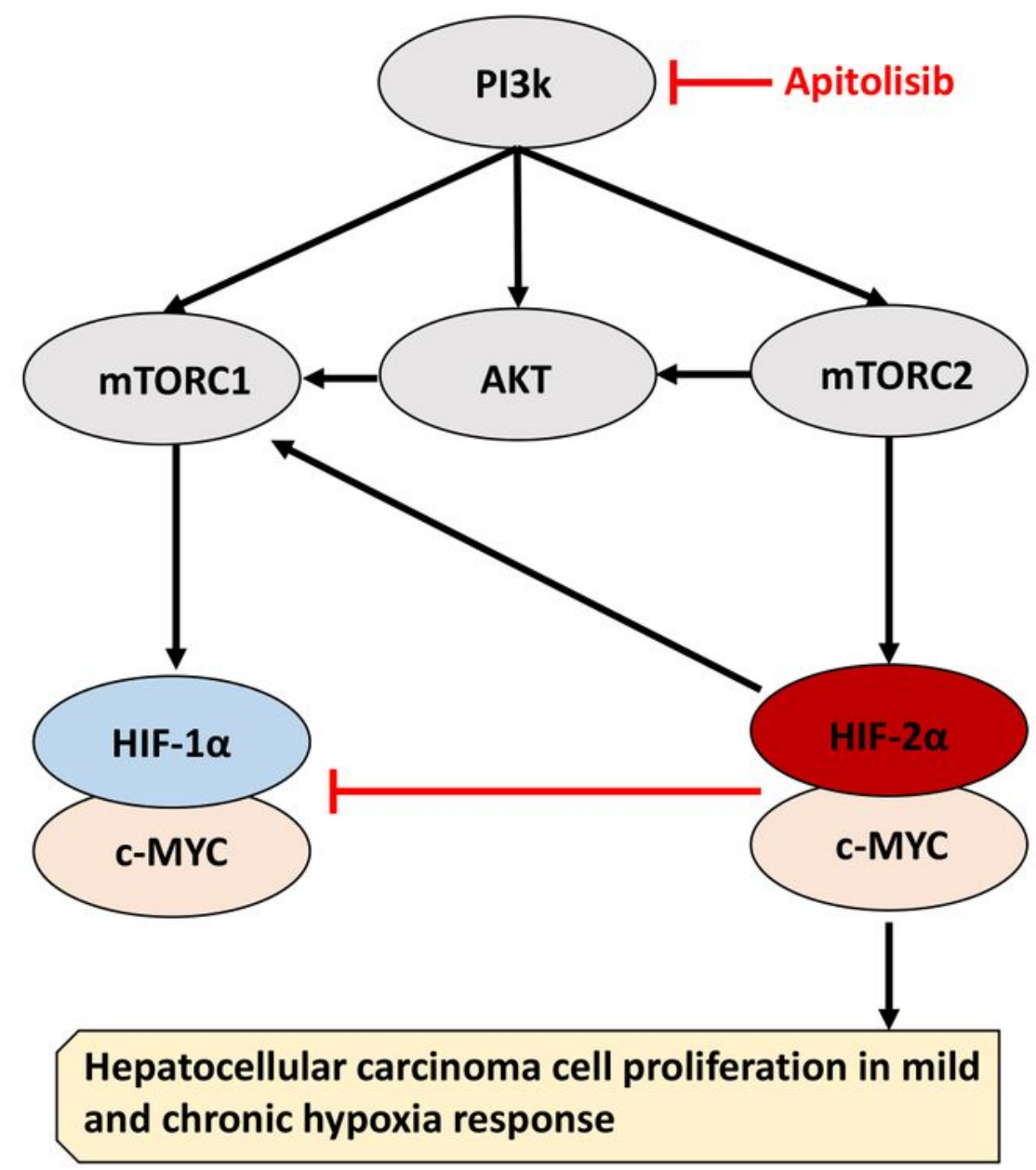

Figure 1

$\mathrm{PI} 3 \mathrm{~K} / \mathrm{mTORC} 2$ regulated HIF-2a interacts with c-MYC through competition with HIF-1a in mild chronic hypoxic hepatocellular carcinoma cell. 


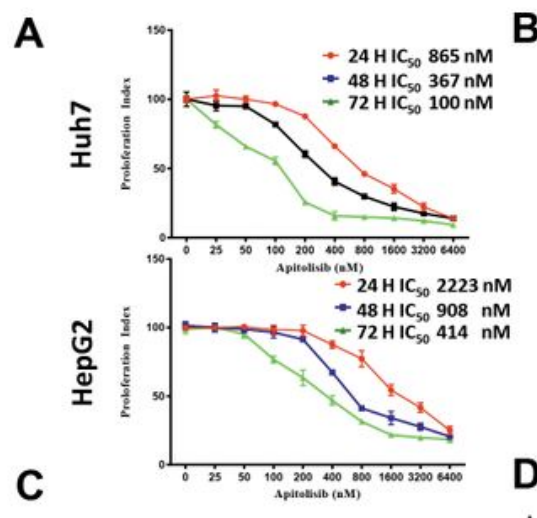

B
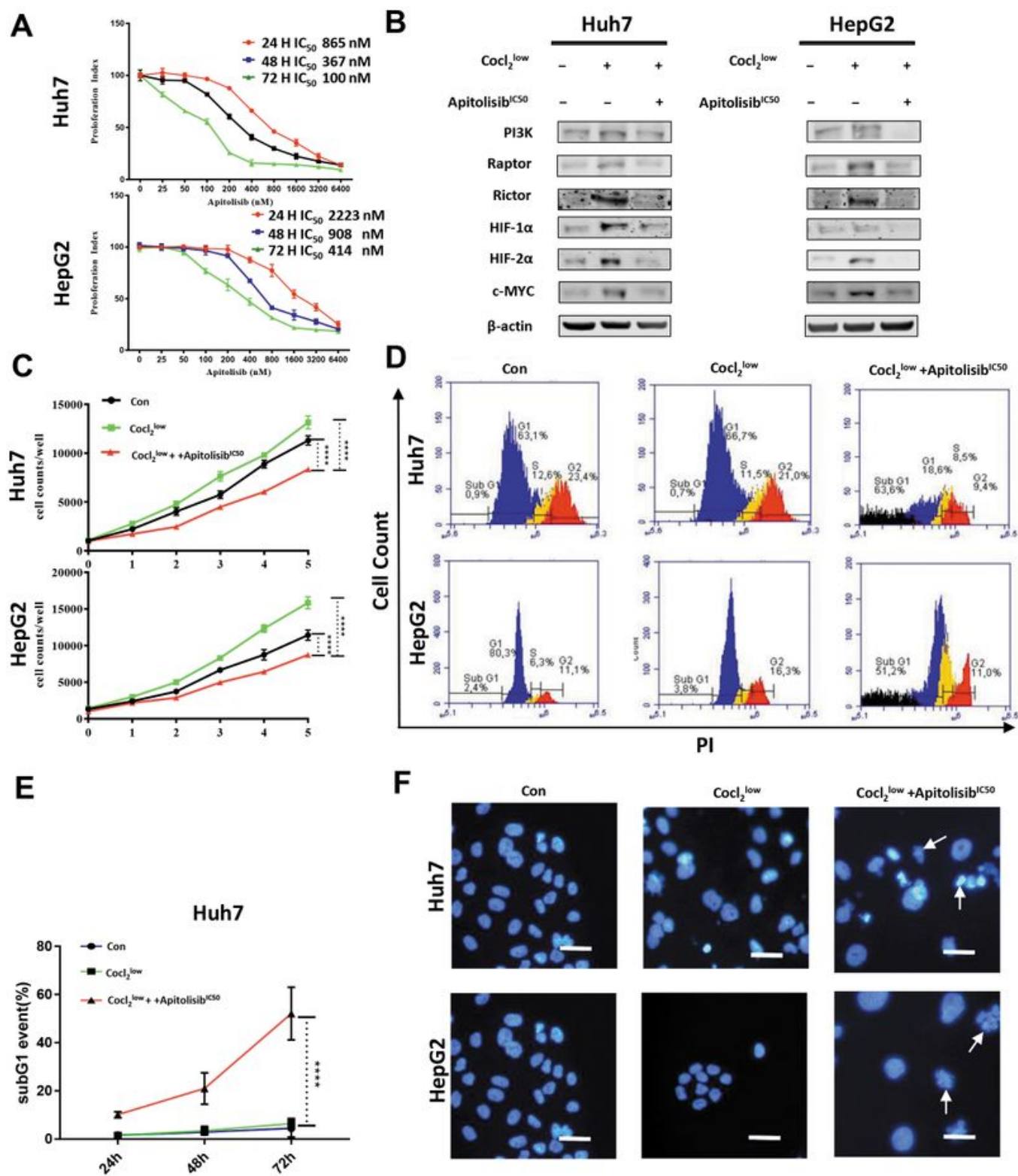

$\mathbf{F}$
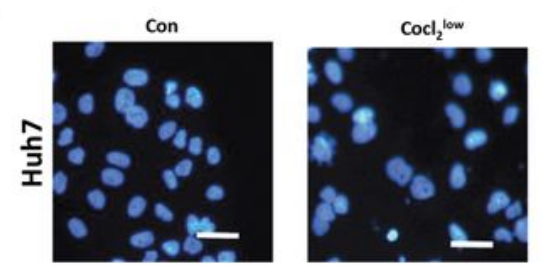

$\mathrm{Cocl}_{2}^{\text {low }}+$ Apitolisib ${ }^{1 \mathrm{CSO}}$
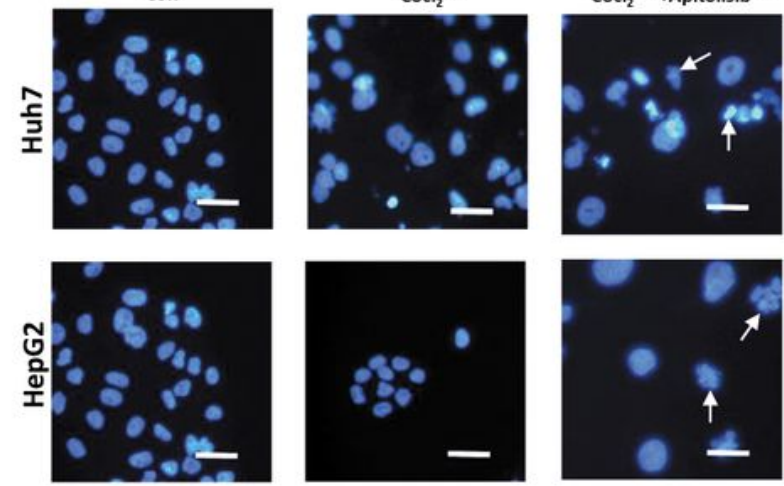

G
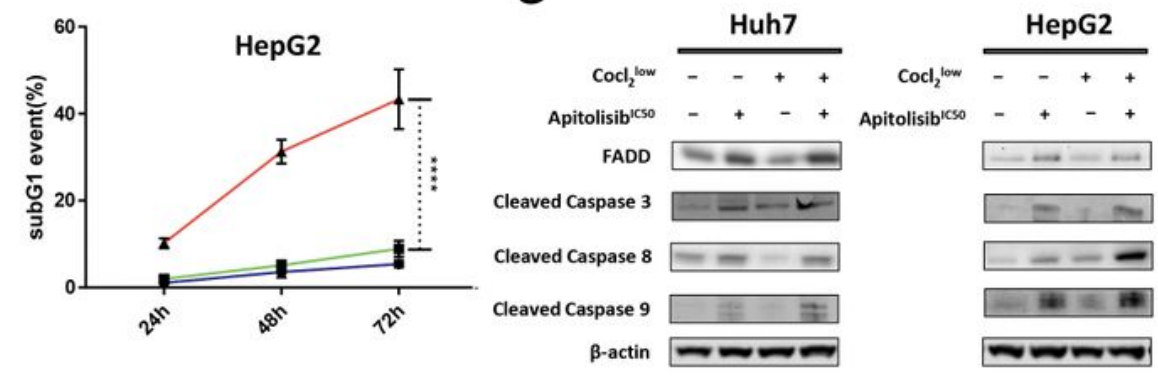

Figure 2

PI3K inhibitor Apitolisib causes a reduction of cell viability and induces HCC cells to apoptosis in hypoxia. a The effect of increasing concentrations of Apitolisib on cell viability. b The expression of PI3k, Raptor, Rictor HIF-1a, HIF-2a, and c-MYC in Huh7 and HepG2 treated by Cocl2 at Cocl2low and ApitolisibIC50 for 72 hours. c Cell proliferation curve of Huh7 and HepG2 treated by ApitolisibIC50 in mild hypoxia for 6 days. d,e Apoptosis detection via staining with propidium iodide (PI) using flow cytometry. Huh7 and 
HepG2 were treated by Cocl2low combined with ApitolisibIC50 for $72 \mathrm{~h}$. f Fluorescence microscopy features after DPAl staining showing nuclear fragmentation in HCC cells treated by ApitolisibIC50 in mild hypoxia for 72 h. Magnification: $\times 20$. g High expression of FADD, cleaved caspase-3, cleaved caspase-8, and cleaved caspase-9 in HCC cells treated by Cocl2low with, or without ApitolisibIC50 for $72 \mathrm{~h}$. line charts quantify the results as mean and SD. ${ }^{* \star *} p$, ${ }^{* \star} p$, and ${ }^{* \star} p<0.01$, and ${ }^{*} p<0.05$ vs. the control cells. ns, no significance.

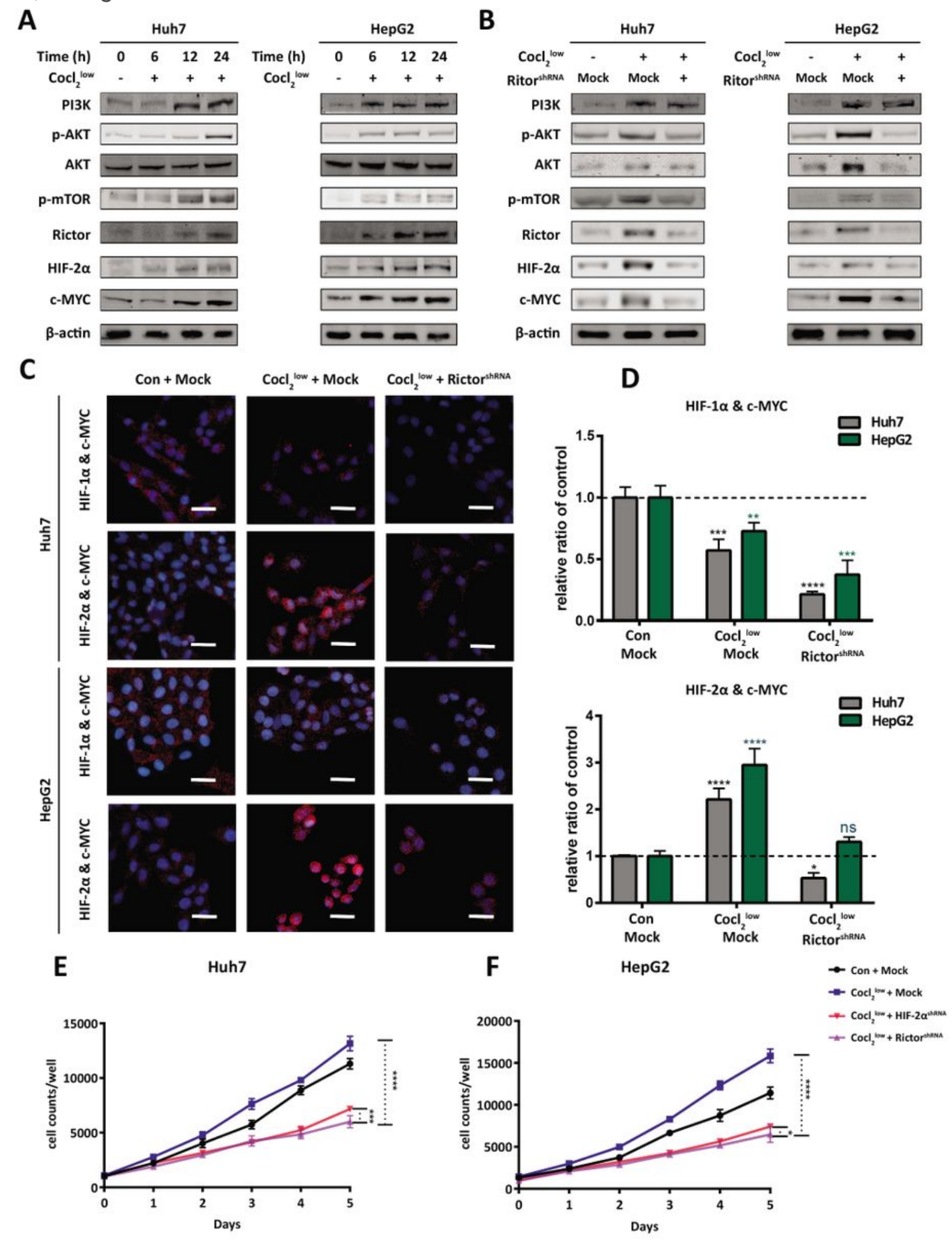

Figure 3 
$\mathrm{PI} 3 \mathrm{~K} / \mathrm{mTORC2}$ regulates HIF-2 $\mathrm{a}$ in mild and chronic hypoxia. a The up-regulated expressions of HIF-2a, cMYC, and PI3k pathway: PI3K, p-AKT, AKT, p-mTOR, and Rictor in Cocl2low treated Huh7 and HepG2 at 24, 48, and $72 \mathrm{~h}$. b Rictor knockdown inhibited the expression of Rictor, p-mTOR, and downstream proteins HIF-2a, c-MYC, AKT, and p-AKT. c,d Representative pictures and statistics of PLA assay to detect interaction of HIF-2a/c-MYC and HIF-1a/c-MYC in shRictor transfected hypoxic HCC cells. e,f Cell proliferation curve of shHIF-2a or shRictor transfected Huh7 and HepG2 in mild hypoxia for 6 days. Bar graphs and line charts quantify the results as mean and SD. ${ }^{\star \star \star \star} p$, ${ }^{\star \star \star} p$, and ${ }^{\star \star} p<0.01$, and ${ }^{*} p<0.05$ vs. the control cells. ns, no significance. 
A

B
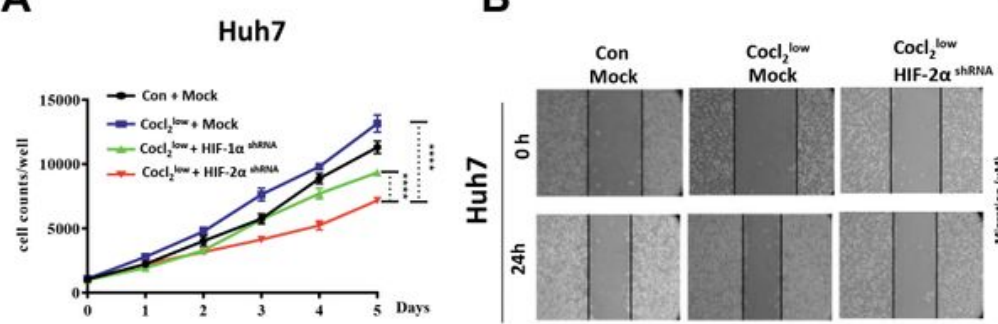

C
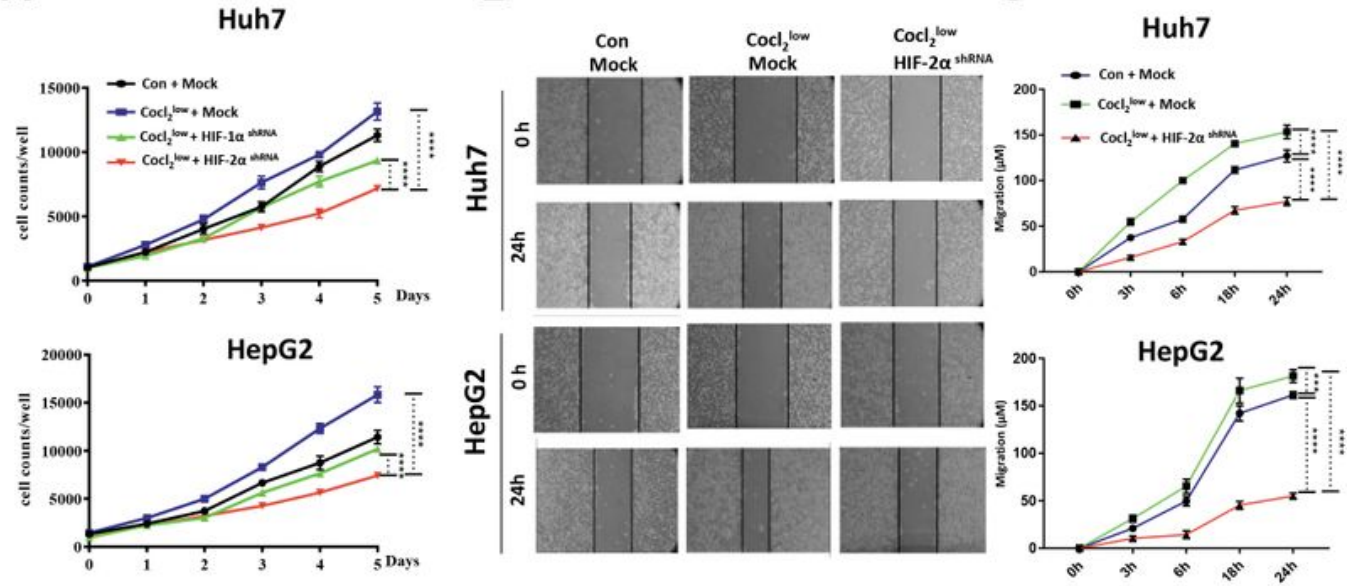

D
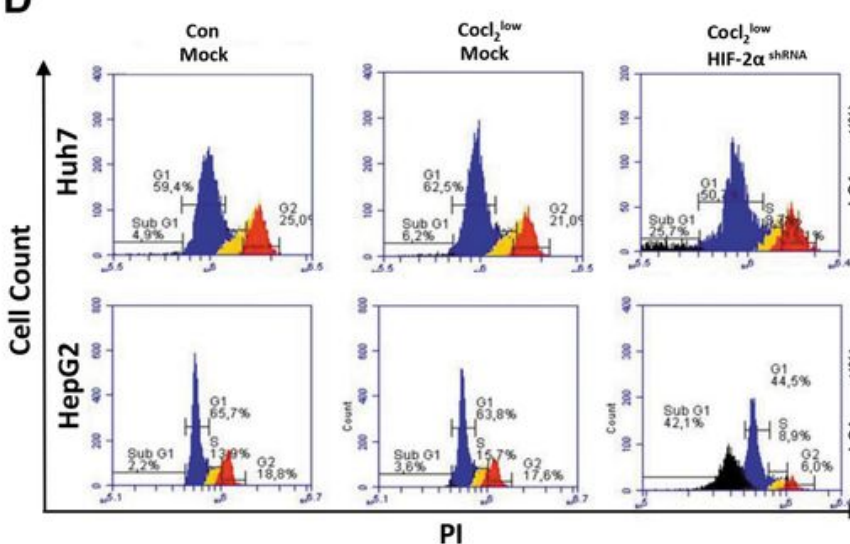

E
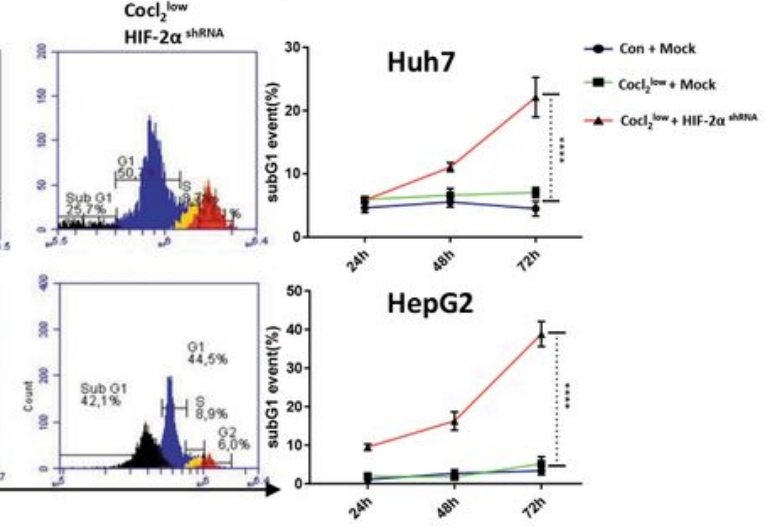

$\mathbf{F}$

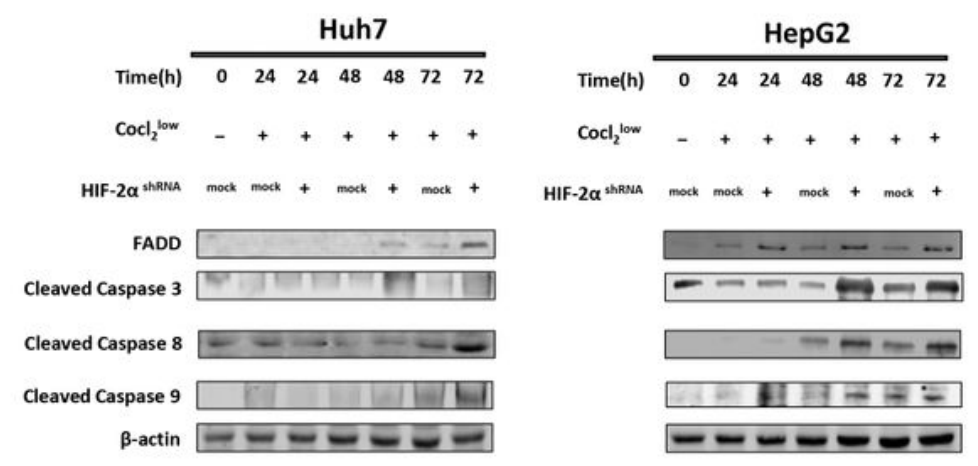

\section{Figure 4}

HIF-2a knockdown inhibits mild hypoxic cell proliferation and sensitize HCC cells to hypoxia-induced apoptosis. a Cell proliferation curve of transfected Huh7 and HepG2 in mild hypoxia for 6 days. b,c Representative pictures and statistics of scratch wound assay about the migration ability of transfected HCC cells in mild hypoxia. d,e Apoptosis detection via staining with propidium iodide (PI) using flow cytometry. Untreated and transfected Huh7 and HepG2 were treated with Cocl2low for 72 h. f High 
expression of FADD, cleaved caspase-3, cleaved caspase-8, and cleaved caspase-9 in transfected Huh7 and HepG2 treated with Cocl2low for 24,48 , and $72 \mathrm{~h}$. line charts quantify the results as mean and SD. ${ }^{* * * *} p,{ }^{* *} p$, and ${ }^{* *} p<0.01$, and ${ }^{*} p<0.05$ vs. the control cells. ns, no significance.

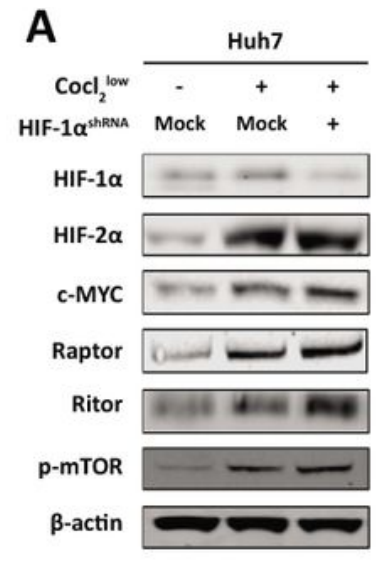

C

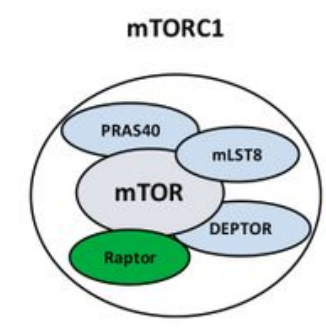

mTORC2

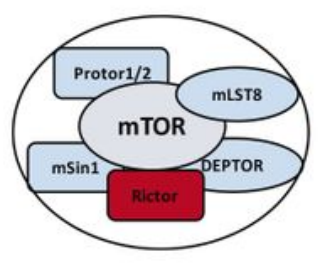

E

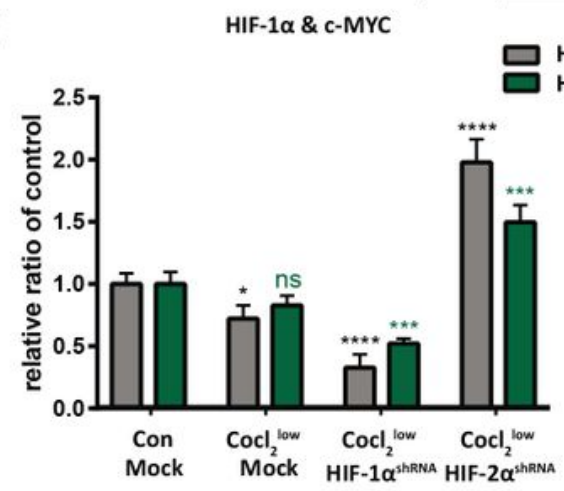

D

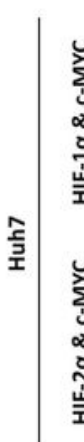

B

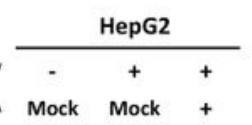

$\mathrm{Cocl}_{2}^{\text {low }} \frac{\text { Huh7 }}{-}++$

EPAS-1 ${ }^{\text {shRNA }}$ Mock Mock +

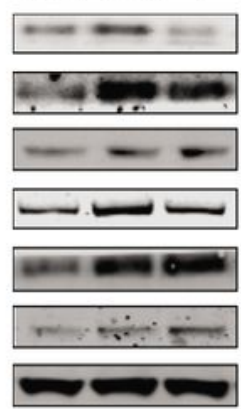

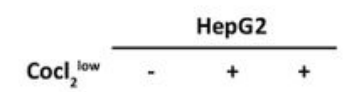
EPAS-1 $1^{\text {shRNA }}$ Mock Mock +

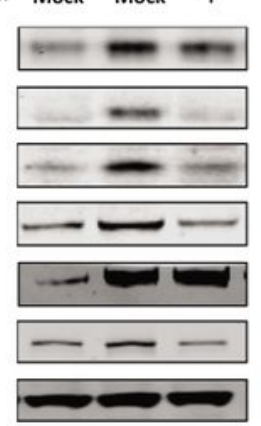

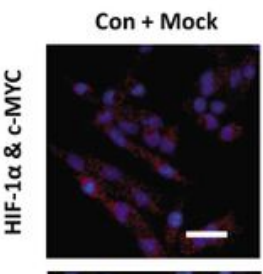

$\mathrm{Cocl}_{2}^{\text {low }}+$ Mock
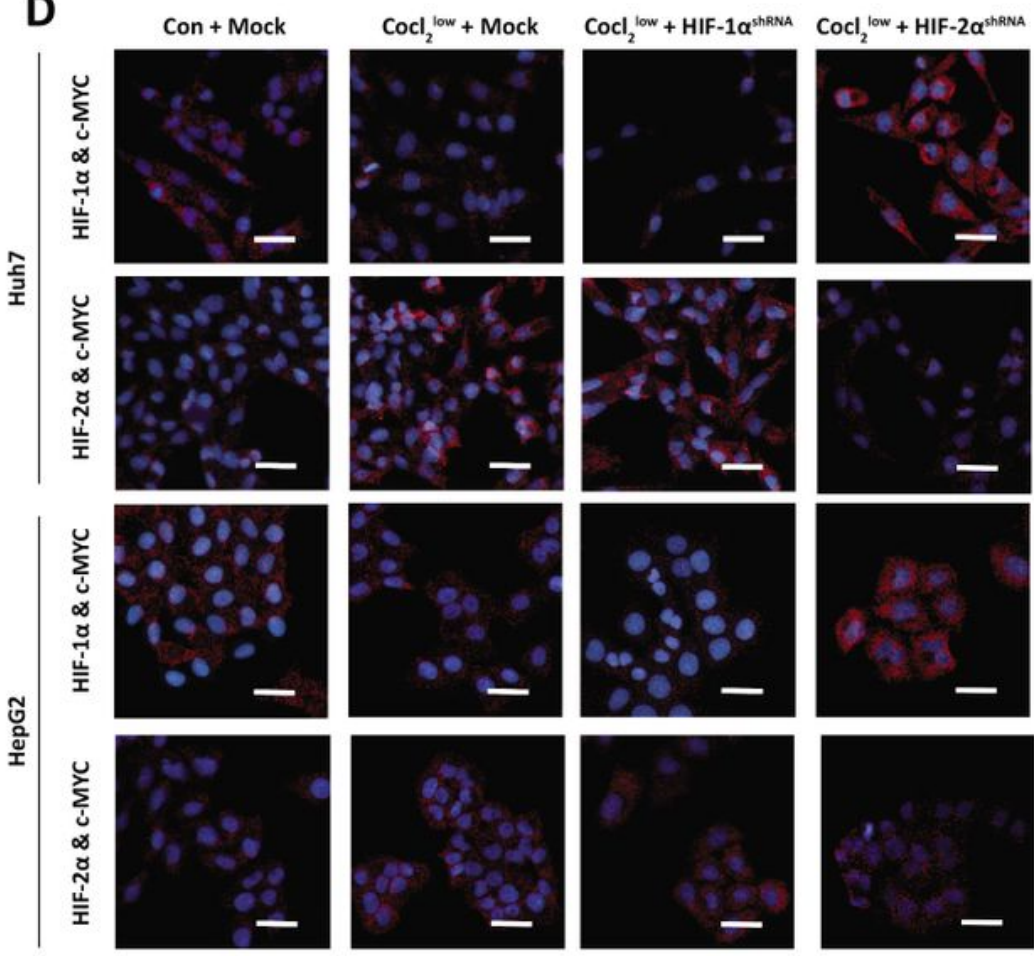

$\mathbf{F}$

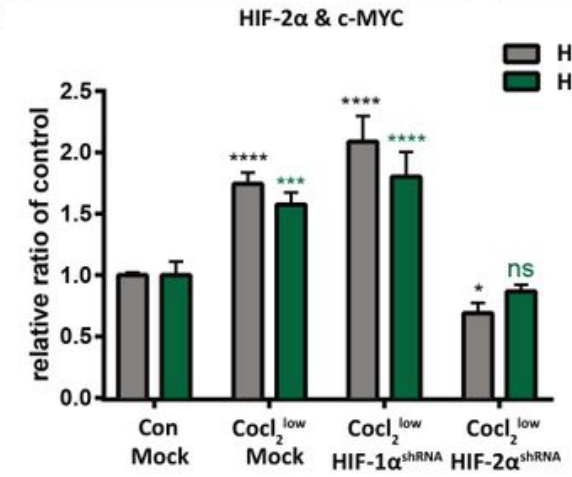

Figure 5

HIF-2a regulates the expression of c-MYC through competition with HIF-1a for c-MYC binding. a,b The expression of HIF-1a, HIF-2a, c-MYC, Raptor, Rictor, and p-mTOR in hypoxic Huh7 and HepG2 transfected 
by shRNA targeting HIF-1a and HIF-2a. c The structure of two complexes of mTOR: mTORC1 and mTORC2. d Representative pictures of PLA assay to detect interaction of HIF-2a/c-MYC and HIF-1a/cMYC in shHIF-1a or shHIF-2a transfected hypoxic HCC cells. e,f PLA data analysis of target protein binding rate in transfected cells after indicated treatments. Bar graphs quantify the results as mean and SD. ${ }^{* * *} p,{ }^{* *} p$, and ${ }^{* *} p<0.01$, and ${ }^{*} p<0.05$ vs. the control cells. ns, no significance.
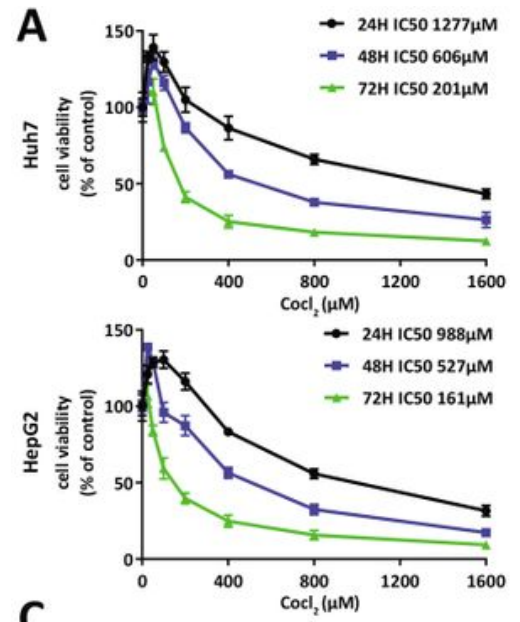

C
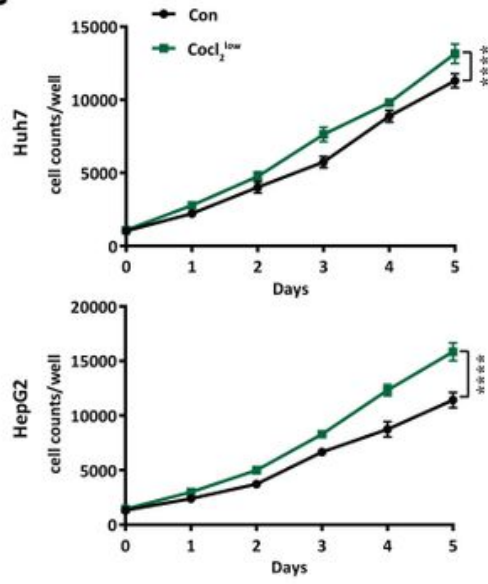

E

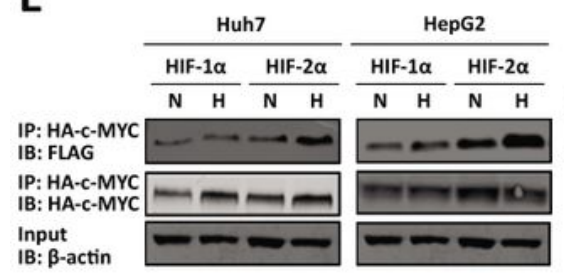

Input

IB: $\beta$-actin

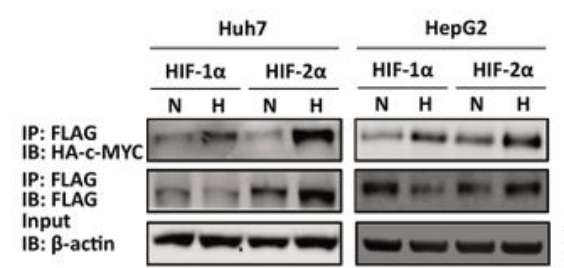

B

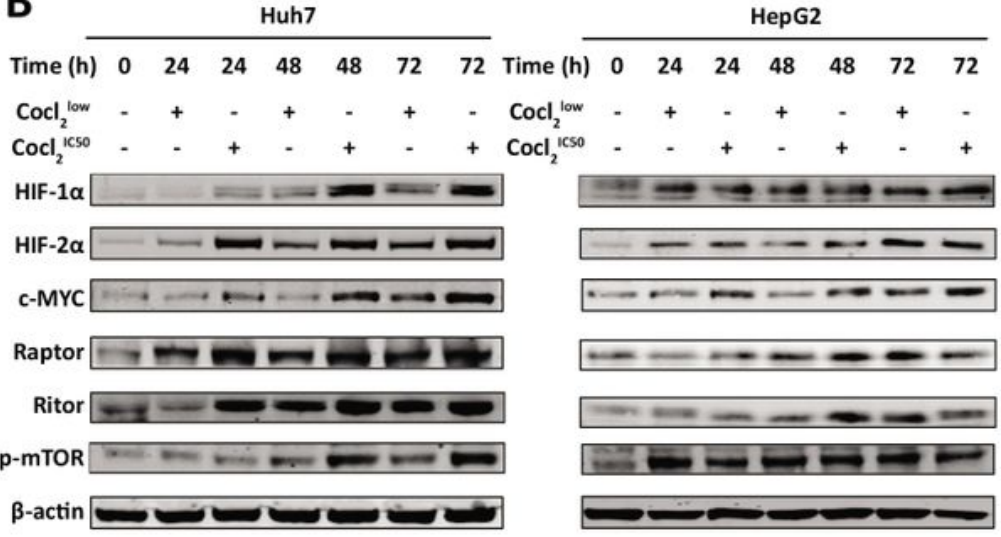

D
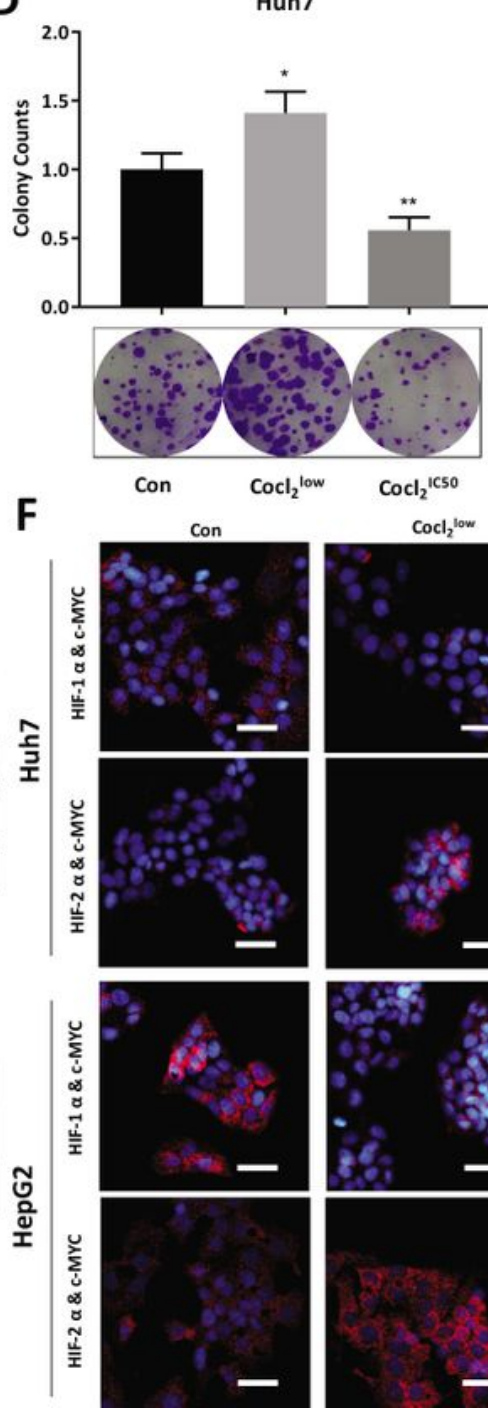
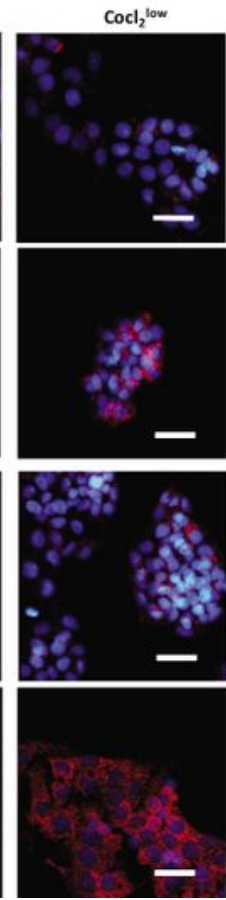

HepG2

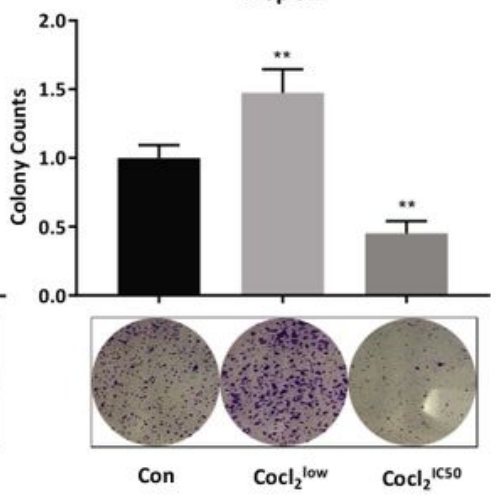

HIF- $1 \alpha \&$ C-MYC
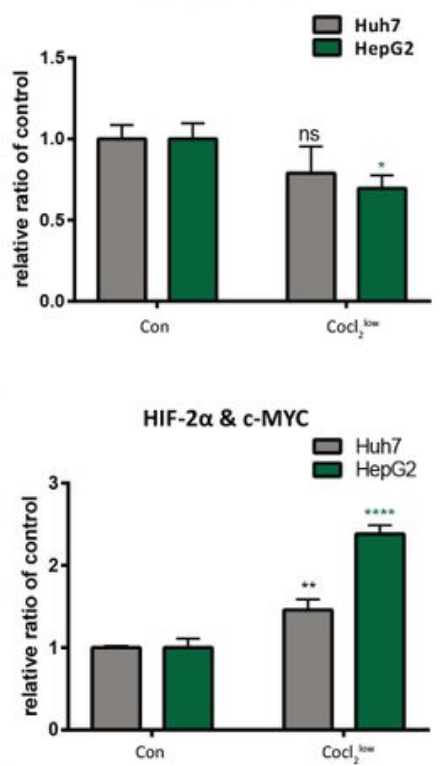

Figure 6 
Interaction of HIF-2a/c-MYC and noninteraction HIF-1a/c-MYC in hypoxic HCC cell proliferation. a The effect of increasing concentrations of Cocl2 on cell viability. b Activation of HIF-1a, HIF-2a, c-MYC, Raptor,

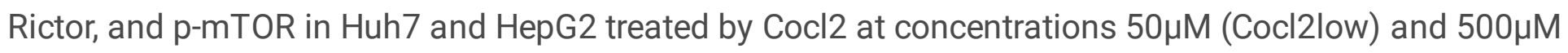
(Cocl2IC50) for 24, 48, and 72 hours. c Cell proliferation curve of Huh7 and HepG2 in mild hypoxia for 6 days. $d$ Representative pictures of colony formation of Huh7 and HepG2 cells, and colony count, after indicated treatments. ef Representative pictures of interaction of HIF-2a/c-MYC and noninteraction HIF$1 \mathrm{a} / \mathrm{c}-\mathrm{MYC}$ and quantities count in PLA assay. Bar graphs and line charts quantify the results as mean and SD. ${ }^{* \star \star \star} p$, ${ }^{\star \star \star} p$, and ${ }^{\star \star} p<0.01$, and ${ }^{*} p<0.05$ vs. the control cells. ns, no significance. 
A

A HIF-1
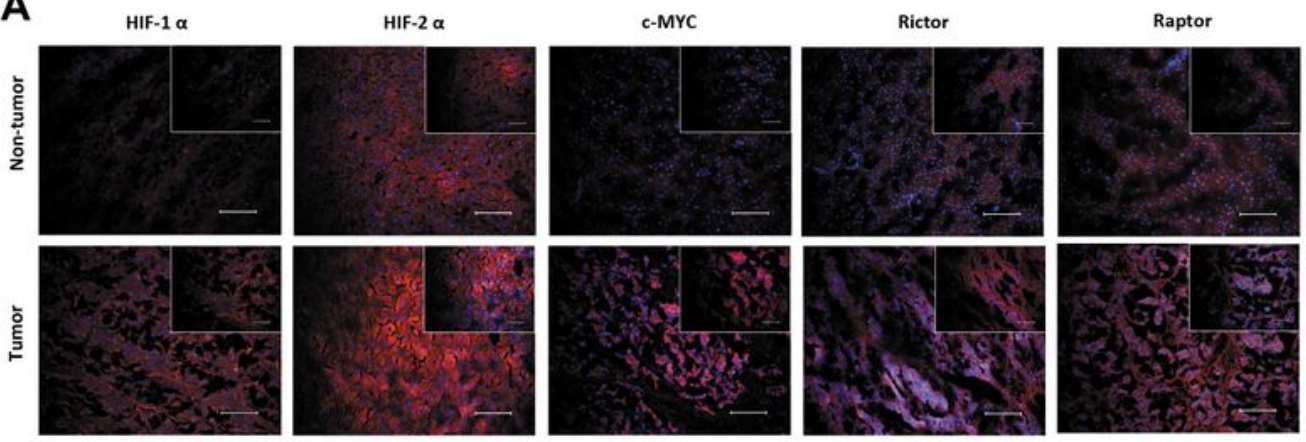

B

C

\section{E}
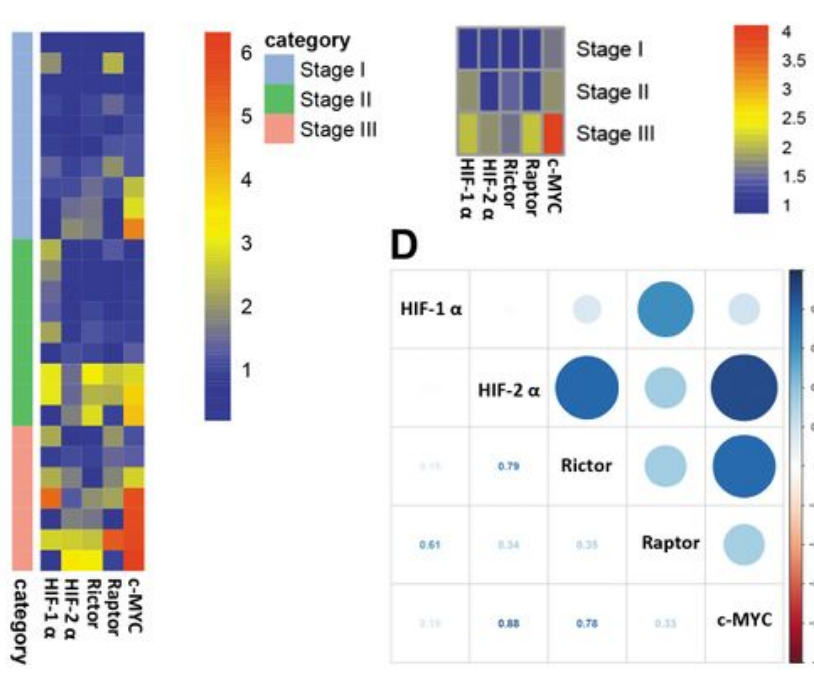

D
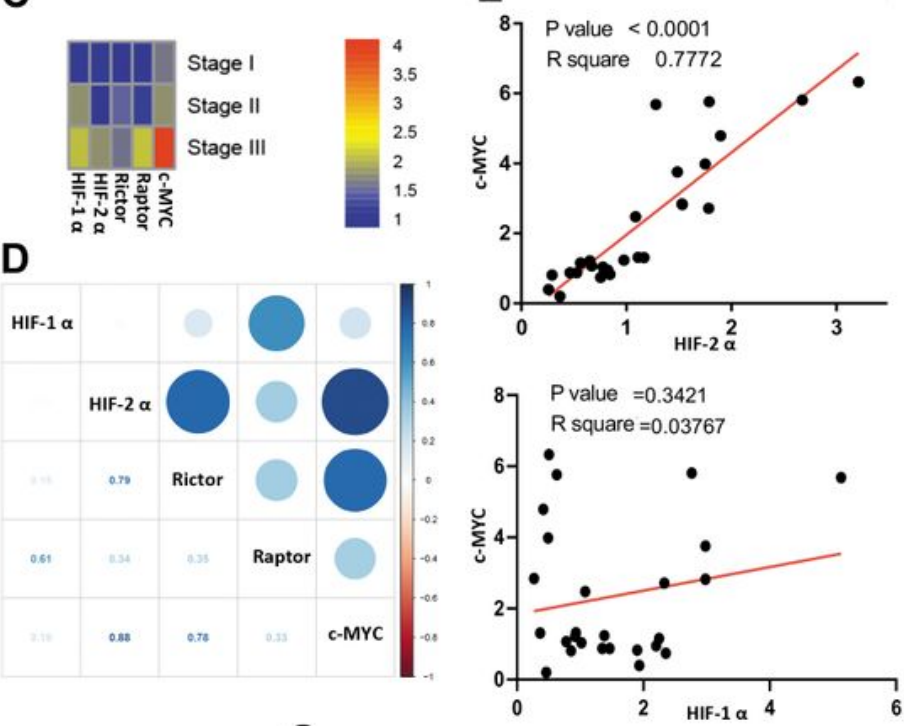

$\mathbf{F}$

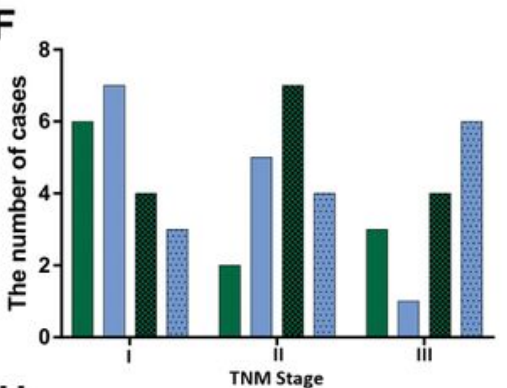

G

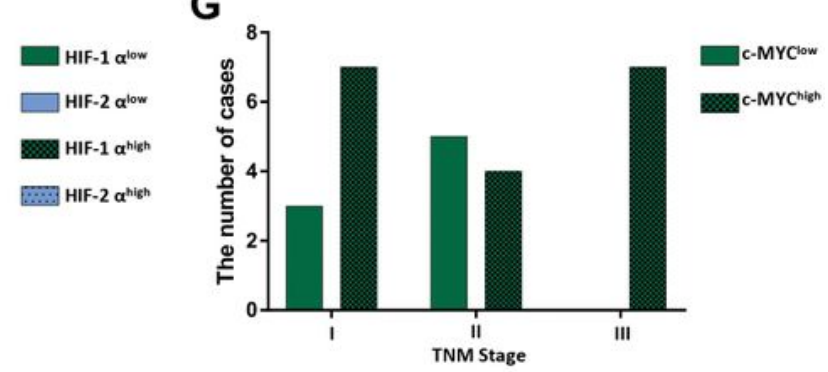

H
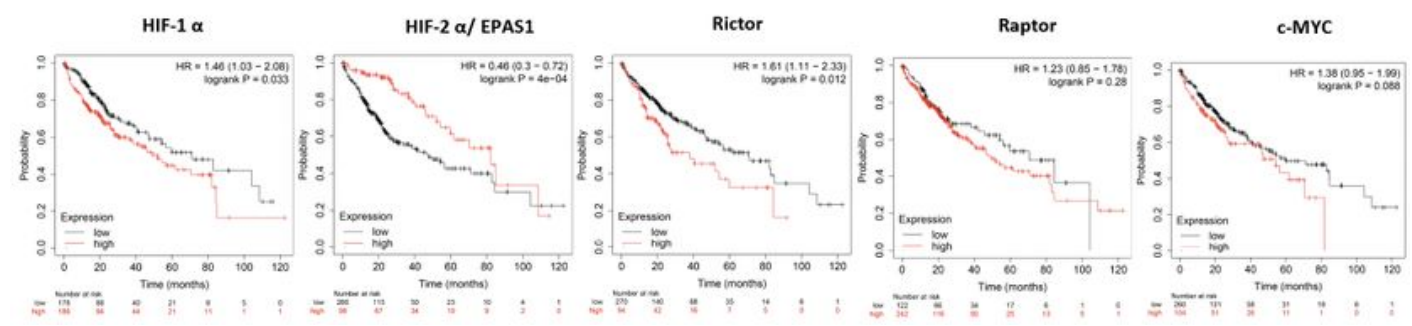

\section{Figure 7}

The expressions and correlations of HIF-1/2a, c-MYC, Raptor, and Rictor in HCC patients. a The representative immunofluorescence pictures of targets staining in tumor tissue and the corresponding non-tumor tissue. b, c Heatmap of the expression ratio of targets in tumor tissue compared to the corresponding non-tumor tissue, and average expression ratio in UICC stages. $d$ Correlation matrix of associations between these targets. e Linear correlation analysis of HIF-1a/c-MYC and HIF-2a/c-MYC. f,g 
The number of HCC cases with low or high expressions of HIF-1a, HIF-2a, and c-MYC in different UICC stage. h Kaplan-Meier survival analysis of HIF-1/2a, c-MYC, Raptor, and Rictor based on the HCC public gene dataset. Magnification, $\times 20$ and $\times 40$ (insets); Scale bar, $100 \mu \mathrm{m}$, and $50 \mu \mathrm{m}$ (insets).

\section{Supplementary Files}

This is a list of supplementary files associated with this preprint. Click to download.

- sfigure3.pdf

- sfigure3.pdf

- sfigure2.pdf

- sfigure2.pdf

- Sfigure1.pdf

- Sfigure1.pdf 